

\section{DISCLAIMER}

This report was prepared as an account of work sponsored by an agency of the United States Government. Neither the United States Government nor any agency Thereof, nor any of their employees, makes any warranty, express or implied, or assumes any legal liability or responsibility for the accuracy, completeness, or usefulness of any information, apparatus, product, or process disclosed, or represents that its use would not infringe privately owned rights. Reference herein to any specific commercial product, process, or service by trade name, trademark, manufacturer, or otherwise does not necessarily constitute or imply its endorsement, recommendation, or favoring by the United States Government or any agency thereof. The views and opinions of authors expressed herein do not necessarily state or reflect those of the United States Government or any agency thereof. 


\section{DISCLAIMER}

Portions of this document may be illegible in electronic image products. Images are produced from the best available original document. 
Reference to a company or product name does not imply approval or recommendation of the product by Union Carbide Corporation or the U.S. Atomic Energy Commission to the exclusion of others that may meet specifications.

Printed in the United States of America. Available from National Technical Information Service

U.S. Department of Commerce

5285 Port Royal Road, Springfield, Virginia 22151

Price: Printed Copy $\$ 4.00$; Microfiche $\$ 1.45$

This report was prepared as an account of work sponsored by the United States Government. Neither the United States nor the United States Atomic Energy Commission, nor any of their employees, nor any of their contractors, subcontractors, or their employees, makes any warranty, express or implied, or assumes any legal liability or responsibility for the accuracy, completeness or usefulness of any information, apparatus, product or process disclosed, or represents that its use would not infringe privately owned rights. 


\title{
A RAPID FIELD TEST FOR MOCA
}

\author{
W. C. Dietrich
}

\section{Oak Ridge Y.12 Plant}

P.O. Box Y. Oak Ridge, Tennessee 37830

Date Issued - May 14, 1974

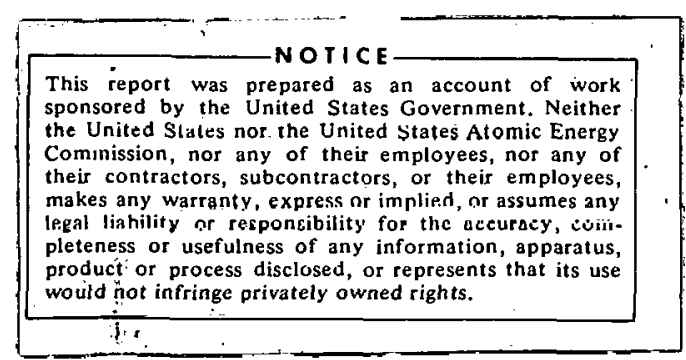

Prepared for the U.S. Atomic Energy Commission Under U.S. Government Contract W.7405-eng-26 


\begin{abstract}
A rapid color test has been developed for methylene-bis-ortho-chloroaniline (MOCA) by itself and in Adiprene L-100 resin. MOCA, on a polyester substrate, reacts with chloranil in chlorobenzene to give a blue color with an intensity that is proportional to the MOCA content.

Color-test sensitivity is magnified for MOCA/resin systems by the presence of reactive MOCA residues in incompletely cured resin polymers.
\end{abstract}


CONTENTS

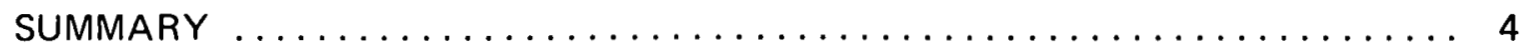



A FIELD TEST FOR MOCA $\ldots \ldots \ldots \ldots \ldots \ldots \ldots \ldots \ldots \ldots \ldots \ldots \ldots \ldots \ldots \ldots \ldots \ldots \ldots \ldots$

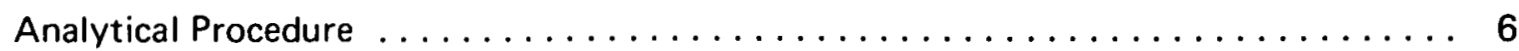

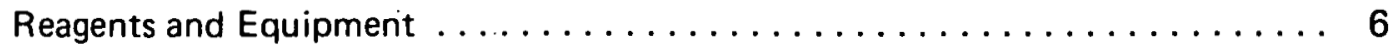

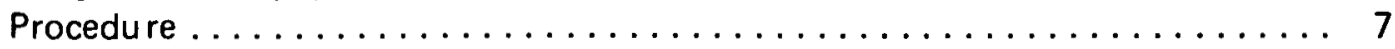

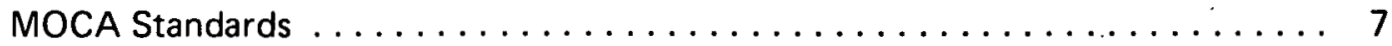

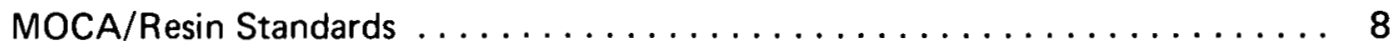

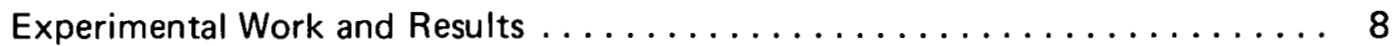

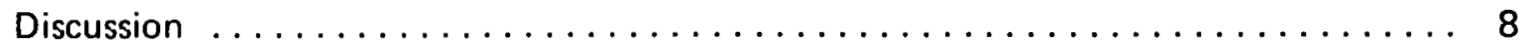

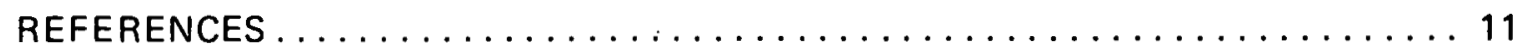

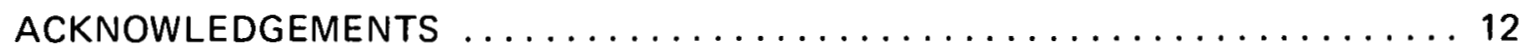




\section{SUMMARY}

$A$ rapid color test was developed for methylene-bis-ortho-chloroaniline (MOCA) and MOCA in MOCA-cured Adiprene L-100 resin. MOCA, impregnated on polyester spunbonded paper or polyester cloth, reacted with chloranil in chlorobenzene to yield a blue color with an intensity that was proportional to the MOCA content.

The lower limit of the test was about $25 \mu \mathrm{g}$ MOCA for pure MOCA. Color-test sensitivity was magnified for MOCA/resin systems by the presence of reactive MOCA residues in incompletely cured resin polymers. 


\section{INTRODUCTION}

Methylene-bis-ortho-chloroaniline (MOCA) is an important curing agent employed in the formation of resin from Adiprene L-100 urethane rubber. Recently, the Occupational Safety and Health Administration (OSHA) had listed MOCA as a carcinogen and required careful monitoring of work areas involving the use of MOCA.(1) Therefore, a rapid field test was needed for the detection of MOCA by itself and in the presence of MOCA-cured Adiprene L-100 resin.

A search of the literature ${ }^{(2)}$ revealed that ortho-chloroaniline could be detected on silica gel as a blue color upon reacting with chloranil (2,3,5,6-tetrachloro-1,4-benzoquinone) in chlorobenzene.

Since ortho-chloroaniline is a major constituent of MOCA, it appeared that chloranil might react with MOCA and thus support a color test. Experimentation was initiated at the Oak Ridge $\mathrm{Y}-12$ Plant $(\mathrm{a})$ to explore the possibility of estimating MOCA with chloranil on substrates other than silica gel.

(a) Operated by the Union Carbide Corporation's Nuclear Division for the US Atomic Energy Commission. 


\section{A FIELD TEST FOR MOCA}

ANALYTICAL PROCEDURE

\section{Reagents and Equipment}

Important reagents in the color test were:

Chloranil Solution - Chloranil $(0.2 \mathrm{~g})$ in 100 milliliters of chlorobenzene.

Isopropyl Achohol

Acetone

Tetrahydrofuran

Items of equipment included:

Sampling Paddle - A piece of spunbonded polyester paper (DuPont, Style 2033) cut into a general paddle shape with a 2-centimeter-square blade (sample section) and a 0.5-centimeter-wide by 4-centimeter-long handle (wick section) (Figure 1).



Figure 1. GRADED CONCENTRATION OF MOCA ON POLYESTER TEST PAPER. 
Sampling Swatch - Piece of undyed $100 \%$ polyester cloth cut into a one-inch by four-inch rectangular shape. This cloth is available in the fabric section of most department stores.

\section{Procedure}

General Considerations - The procedure for estimating MOCA content is dependent upon the purpose of the evaluation. The most valuable purpose is a "clean/not clean" test of equipment and work area surfaces. Another purpose involves a semiquantitative estimation of MOCA or the extent of polymerization of MOCA/resin mixtures.

It is essential to the estimation of the extent of contamination of involved surfaces that MOCA or MOCA/Adiprene L-100 resin mixtures be transferred to the polyester paper or cloth. Dry paper or cloth is often inadequate in picking up sample material by friction alone. Wetting the polyester with isopropyl alcohol, prior to rubbing the test area, facilitates the transfer of sample material. Vigorous treatment is sometimes needed, and acetone or tetrahydrofuran replaces the alcohol. Acetone dissolves any MOCA, and tetrahydrofuran dissolves any resin residues. Discretion is required in use of these latter solvents, since solubility tests revealed that 15 wt \% of the polyester cloth or paper dissolved when totally immersed for 15 minutes. Exposure of the polyester for a few minutes to these latter solvents will not deteriorate the test.

Clean/Not Clean Test for MOCA - Testing for MOCA is conducted as follows: Moisten a sampling paddle (or swatch) with isopropyl alcohol, acetone, or tetrahydrofuran and scrub the surface to be tested with the blade section. Permit the solvent to evaporate, then dip one corner of the blade into the $0.2 \%$ chloranil-in-chlorobenzene solution and permit the solution to migrate through the blade area. Dry the paddle with a jet of "air" (eg, Freon or nitrogen) and look for any blue color. Caution: Do not perform this test in daylight (see Discussion). If a blue color is observed, continue cleaning the test surface.

Semiquantitative Estimation of MOCA or Extent of Polymerization of MOCA/Adiprene L-100 Resin Residues - Estimates of MOCA can be achieved as follows: Obtain $0.1 \mathrm{~g}$ of residue from the MOCA work area and dissolve this sample in 100 milliliters of acetone or dissolve $0.5 \mathrm{~g}$ of MOCA/Adiprene L-100 resin in $10 \mathrm{ml}$ of tetrahydrofuran. Add $0.1 \mathrm{ml}$ of either sample solution to the center of the blade area of a paddle. Dry the paddle, then dip one lower corner of the blade into the color development reagent and permit the solution to migrate up 2/3 the length of the wick. Dry the paddle with a jet of "air" (Freon or nitrogen) and compare any blue color to a series of "standard" paddles. Caution: Do not perform this test in daylight (see DISCUSSION).

\section{MOCA Standards}

To prepare a MOCA standard, accurately weigh a $0.5-\mathrm{g}$ aliquot of pure MOCA and dissolve this aliquot in $100 \mathrm{ml}$ of acetone. Pipette $5,10,25$, and $50 \mu$ l aliquots from this MOCA solution on the center of a blade of a series of paddles. Process the paddles according to the developed color test, align them in a graded color intensity series, and.photograph them. Be sure to maintain color fidelity. 
MOCA/Resin Standards

To prepare a MOCA/resin standard, determine a weight percent value for MOCA required as a curing agent for the Adiprene L-100 urethane rubber ( 8 wt \% in this study). Estimate from this weight percent the MOCA aliquot needed to cure $50 \mathrm{~g}$ of the urethane rubber. Heat the aliquot to $100^{\circ} \mathrm{C}$ and add the melt to the urethane rubber labout $24^{\circ} \mathrm{C}$. Blend the mixture thoroughly and periodically remove $0.5-\mathrm{g}$ aliquots trom this mixture and immediately dissolve these alluuvis inl $10 \mathrm{lill}$ ul telialiydiuluian (Table 1). Next, remove $0.1-\mathrm{ml}$ aliquots from each solution and transfer them to the center area of a blade. Develop the paddle according to the test procedure, arrange the paddles in a graded color intensity series, and photograph the paddles (Figure 1).

\section{Experimental Work and Results}

A graded series of MOCA "standards" was prepared by dissolving $0.5 \mathrm{~g}$ of pure MOCA in $100 \mathrm{ml}$ of acetone and adding $5,10,25$, and $50 \mu \mathrm{l}$ of this solution to the center of the blades of a series of paddles. The paddles were then processed according to the test procedure, arranged in a color intensity series, and photographed (Figure 1).

A graded polymerization series of MOCA-cured Adiprene L-100 resin "standard solutions" was prepared. An aliquot of four grams of MOCA was heated to $110^{\circ} \mathrm{C}$ and added to $50 \mathrm{~g}$ of Adiprene L-100 urethane rubber at $24^{\circ} \mathrm{C}$. The mixture was thoroughly stirred and a 0.5-g aliquot was periodically removed from the mixture and immediately dissolved in $10 \mathrm{ml}$ of tetrahydrofuran to inhibit the polymerization. A $0.1-\mathrm{ml}$ aliquot was removed from each solution and added to the center of a blade of a series of paddles. Then, the paddles were processed according to the developed test procedure, arranged according to color intensity, and photographed (Figure 1). Aliquots were also analyzed for free MOCA content by gel permeation chromatography. Results of these tests are presented in Table 1.

A color test of compounds of related interest revealed an intense wine color for meta-phenylene diamine, an intense blue color for methylene diamine, and a very faint yellow color for toluene-di-isocyanate.

\section{DISCUSSION}

A literature reference ${ }^{(2)}$ described how aromatic amines react with chloranil and silica gel acid groups to give intensely colored compounds. The silica gel existed as a coating supported on glass plates. In this reference, ortho-chloroaniline was stated to give an intense blue color when reacted" with chloranil in the presence of silica gel groups. Since ortho-chloroaniline is a major constituent of MOCA, the color reaction of ortho-chloroaniline with chloranil on silica gel suggested a possible scheme for a color test for MOCA. 
Any direct application of the chloranil/silica gel medium to a MOCA field test appeared impractical due to the inflexibility of the silica gel-coated plates. In a field test, a sampling technique was needed where an affected area could be wiped with some material and the contaminated material tested for MOCA. Ordinary filter paper was excluded by the literature reference, since cellulosive groups would not support the color reaction of aromatic amines with chloranil. Spunbonded polyester paper or cloth contaminated with MOCA yielded an intense blue color upon reacting the MOCA with $0.2 \%$ chloranil in chlorobenzene. A smear of pure Adiprene L-100 urethane rubber on polyester paper or cloth yielded a light pink color with the chloranil-in-chlorobenzene reagent. A similar test for a smear of MOCA-cured Adiprene L-100 resin yielded no detectable color when the resin was completely cured.

These preliminary color tests for smears of MOCA, urethane rubber, and cured resin on polyester material by chloranil in chlorobenzene were conducted in fluorescent light. Under these conditions, the colored compounds were relatively stable for about one hour. Exposure of these developed color areas to sunlight resulted in an extensive and intense color formation that invalidated the test; therefore, the developed color test for MOCA must not be performed in sunlight.

A "standard solution" of MOCA was prepared by dissolving $0.5 \mathrm{~g}$ of MOCA in $100 \mathrm{ml}$ of acetone. Then, aliquots from this solution were added to the blade area of a paddle series and the MOCA color developed according to the established procedure. The paddles were then arranged in order of color intensity and photographed (Figure 1).

A graded polymerization series of MOCA-cured Adiprene L-100 resin "standard pot solutions" was prepared. A pot mixture of $8 \mathrm{wt} \%$ MOCA in Adiprene L-100 urethane rubber was prepared, then aliquots were periodically taken from this pot mixture and dissolved in tetrahydrofuran to inhibit further polymerization. Aliquots were taken from these solutions and added to the blade area of a paddle series, then each paddle was tested for MOCA according to the developed procedure. The paddles were arranged in a color intensity series and photographed (Figure 1). The "standard pot solutions" were also analyzed for free MOCA content by gel permeation chromatography. Results of these tests are presented in Table 1.

The color patterns observed for MOCA only and MOCA in various stages of cured resin were distinctly different (Figure 1). MOCA alone migrated readily from the blade section up the wick section of a paddle, while free MOCA in nearly cured resin appeared essentially fixed to the blade section of a paddle. Also, a correlation of color intensity to micrograms of MOCA on a paddle revealed an apparent marked increase in the color sensitivity of free-MOCA-in-resin samples. Careful consideration of this increased color intensity for free-MOCA-in-resin mixtures suggested that organic groups other than MOCA were reacting with chloranil to give a blue color. The most likely reactive group in this system seemed to be ortho-chloroaniline as a MOCA residue from incompletely cured resin polymers. Abundance of these ortho-chloroaniline polymer terminals would be a function of the degree of polymerization. For example, in the initial stages of the polymerization, polymer chains of a few members and correspondingly many reactive terminals would prevail, while in the final stages of polymerization, polymers of long chains with few reactive terminals would prevail. Therefore, in the case of the MOCA-cured resin system, the color test is really an estimate of the extent of resin polymerization, and a colorless test assures the complete cure of the resin system. 
Initial efforts to accelerate color development in the test for MOCA by spraying the sample specimen with various concentrations of chloranil in chlorobenzene were not successful. However, permitting a $0.2 \%$ chloranil-in-chlorobenzene solution to migrate from a bottom corner of the blade section of a paddle up to $2 / 3$ the length of the wick section and then vigorously sweeping the paper with a gas jet (Freon or nitrogen) resulted in full color development within one minute.

Compounds other than MOCA were tentatively considered and tested with the developed color test. Meta-phenylene diamine gave an intense wine color; methylene diamine gave an intense blue color. Toluene di-isocyanate in large concentrations gave a faint yellow color. This color test appears to be applicable to estimating states of polymerization of isocyanate plus amine-type curing agents.

Experimenters who wish to utilize the developed color test for MOCA may encounter great difficulty in obtaining spunbonded polyester paper. It appears that this paper was initially prepared in several styles as a research endeavor. Samples were distributed, and a unheralded response for orders overwhelmed the production capability. However, nondyed $100 \%$ polyester cloth is a good substitute and can be found in the fabric section of most department stores. Extensive field experience with swatches of polyester cloth proved that this material was adequate. The polyester paper paddles recommended in the procedure provide a denser substrate with improved sample retention and an opaque white background that are advantageous to semiquantitative studies.

The developed color test for MOCA and MOCA/resin systems has been found to be a sensitive, rapid, and an inexpensive method for estimating MOCA contamination in the ficld. 


\section{REFERENCES}

(1) "Title 29-Labor, Chapter XVII-Occupational Safety and Health Administration, Department of Labor. Part 1910-Occupational Safety and Health Standards", Federal Register, 38, (144); July 27, 1973.

(2) Pires, L. M. and Reseria, A. N.; "The Solvent Effect in the Use of Chloranil as a Reagent in the Identification of Aromatic Amines on Silica Gel Thin Layers", Journal of Chromatography, 56, pp 59-67(1971). 


\section{ACKNOWLEDGEMENTS}

The author is indebted to William Everett of the $Y-12$ Health Physics Department for sharing his extensive field experience with the MOCA color test and to Y-12 Plant Laboratory personnel for the gel permeation analyses and for supplying samples of MOCA. and Adiprene $L-100$ resin materials. 


\section{DISTRIBUTION}

Atomic Energy Commission - ORO

Hardaway, J. B., III

Hickman, H. D.

Johnson, W. A.

Zachry, D. S., Jr

Bendix - Kansas City

Knuth, J. A.

\section{Lawrence Livermore Laboratory}

Gaskill, J. R.

Los Alamos Scientific Laboratory

Schulte, H. F.

Whipple, H. O.

Oak Ridge Gaseous Diffusion Plant

Cagle, G. W. (5)

Schultz, N, B.

Wilcox, W. J., Jr

Winkel, R. A.

Oak Ridge National Laboratory

Bolton, N. E.

Doherty, D. G.

Oak Ridge Y-12 Plant

Briscoe, O. W.

Burditt, R. B.

Burkhart, L. E.

Denny, A.

Dietrich, W. C.

Dodson, W. H.

Ebert, T". $\mathrm{H}$.

Everett, W. S., Jr

Traser, R. J.

Johnson, C. E.

Junes, F. W.
Jordan, R. G.

Keith, A. (2)

Kite, H. T.

Kahl, K. G.

Lundin, M. I.

Marrow, G. B.

McLendon, J. D.

Morehead, J. F.

Phillips, L. R.

Rowan, J. H.

Sanders, M.

Schmitt, C. R. (10)

Schreyer, J. M.

Smith, H. F., Jr

Smith, R. D.

Stoner, H. H.

Tewes, W. E.

Weathersby, W. E.

Whitehead, H. D.

Williams, R. D.

Yaggi, W. J./Googin, J. M.

$Y-12$ Central Files (5)

$Y-12$ Central Files (master copy)

$Y-12$ Central Files (route)

$Y-12$ Central Files (Y-12RC)

Paducah Gaseous Diffusion Plant

Levin, R. W.

McDougal, B. E.

Turak, C. W.

Sandia - Albuquerque

Kingsley, W. H.

Sandia - Livermore

Lovell, P. K.

Scholer, G. L.

In addition, this report is distributed in accordance with the category UC-4, Chemistry, as given in the USAEC Standard Distribution Lists for Unclassified Scientific and Technical Reports, TID- 4500 . 